\title{
O professor (ainda) no centro do processo ensino-aprendizagem em Odontologia
}

Luiz Roberto Augusto Noro*; Bárbara Cássia de Santana Farias-Santos*; Pedro Henrique Sette-deSouza $^{* * *}$; Isabel Alves Gomes Pinheiro ${ }^{* * * * *}$; Raul Elton Araújo Borges ${ }^{* * * * *}$; Luana Maria Ferreira Nunes $^{* * * * *}$; Rayanne Karina Silva Cruz ${ }^{* * * *}$; Samara Martins Silva ${ }^{* * * * * *}$

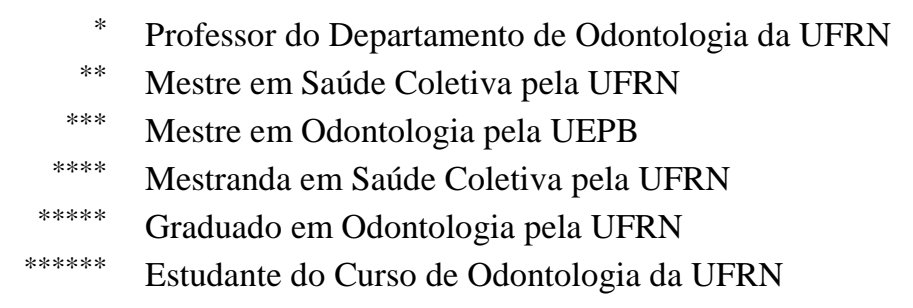

\section{RESUMO}

Há um reconhecimento da necessidade de mudança na educação de profissionais de saúde frente à necessidade de formar profissionais capazes de responder às demandas sociais e com isso trazer melhor qualidade de vida à população. Para isto, é fundamental discutir como o professor se insere neste contexto uma vez que é dele a responsabilidade pela condução do processo educativo. O objetivo deste estudo foi analisar a percepção de alunos do curso de graduação em Odontologia da Universidade Federal do Rio Grande do Norte (UFRN) a respeito do papel do professor no processo ensino-aprendizagem. Trata-se de estudo de natureza qualitativa, realizada por meio da técnica de grupos focais compostos por estudantes regulares dos $2^{\circ}, 3^{\circ}, 4^{\circ}, 8^{\circ}$ e $9^{\circ}$ períodos, no ano 2012. Os estudantes entrevistados enfatizaram o professor como o grande responsável pelo seu aprendizado. Da análise dos dados surgiram quatro categorias: Metodologia adotada pelo professor, Relacionamento professor/aluno como influente no processo de aprendizagem, Falta de autonomia do discente e Formação docente. O estudo revelou que o professor ainda é mantido no centro do processo de ensino em função da passividade dos discentes em não assumir seu papel de corresponsáveis por sua formação, possivelmente pela postura adotada pelo professor, centrada na técnica e com pouca base em metodologias pedagógicas ativas.

Descritores: Ensino. Docentes de Odontologia. Desenvolvimento de Pessoal. Odontologia.

\section{INTRODUÇÃO}

A educação pode ser encarada como uma estratégia de libertação de um povo e por esse motivo não deve ser encarada como uma ação unilateral, engessada, onde há quem ensina e quem aprende, porém, deve ser vista de forma integrada onde os atores do processo mudam de lugar constantemente. Deve ser dinâmica e aberta, livre para ser pensada e repensada em todo o seu percurso. Nesta dimensão, pode ser entendida como importante instrumento de transformação social.

Neste contexto, o papel do professor assume alto grau de relevância, cabendo a ele não apenas a transmissão de conhecimentos, mas também o despertar no aluno da consciência crítica e análise dos problemas que o cercam $^{1}$. Nessa perspectiva de construção do 
conhecimento alguns autores definem que o papel do professor é ajudar os alunos a entenderem a realidade em que se encontram, tendo como mediação para isto o conhecimento. A aprendizagem por sua vez, acontece num entrelaçamento entre informação, conhecimento e saber ${ }^{2}$. Dessa forma, focaliza o aluno e o professor em suas relações, considerando como ocorre o processo de ensinoaprendizagem.

Há um reconhecimento da necessidade de mudança na educação de profissionais de saúde frente à necessidade de formar profissionais capazes de responder às demandas sociais e com isso trazer maior qualidade de vida à população, buscando processos de mudanças na formação de profissionais de saúde e novas formas de trabalhar com o conhecimento. Neste contexto, compreender o papel do professor no âmbito da inovação pedagógica, inerentes ao processo de ensinoaprendizagem, tem ocupado um importante espaço de discussão sobre inovação na área da Saúde ${ }^{3}$.

Esse processo de mudança da educação traz consigo inúmeros desafios, entre os quais, romper com estruturas cristalizadas e modelos de ensino tradicional e formar profissionais de saúde com competências que lhes permitam recuperar a dimensão essencial do cuidado. Um ponto a se discutir seria a formação dos docentes, fundamentais para o ensino. Muitos programas de pós-graduação stricto sensu privilegiam a formação centrada nas técnicas e especialização, colaborando com a perpetuação desse paradigma nas instituições de ensino superior ${ }^{4}$. Essa prática reforça a ideia de quem sabe fazer também sabe ensinar, dando sustentação à lógica do recrutamento dos docentes nas instituições de ensino odontológico ${ }^{5}$.

Sabe-se que a formação do professor de Odontologia deve seguir a mesma linha das atuais Diretrizes Nacionais Curriculares (DCN), pois este é um importante agente para alcançar a transformação do perfil profissional preconizado. Ao defrontar-se com um novo cenário institucional extremamente competitivo e com padrões de docência definidos pelo mercado de trabalho e pelo sistema de saúde, o professor universitário tem, hoje, uma nova exigência de formação, com novos desafios à sua prática ${ }^{6}$. Dessa forma, faz-se necessário propor uma reflexão sobre o real papel do professor no processo de ensino-aprendizagem na formação de profissionais na Odontologia, partindo do princípio que a formação didático-pedagógica do professor universitário e a qualidade da educação superior, em especial nos cursos de Odontologia, começaram a ser questionadas em decorrência das demandas da sociedade em mudança e da presença das $\mathrm{DCN}^{7}$.

Essas percepções podem contribuir para adequada formação em Odontologia que vise à busca do perfil do egresso desejado, suficiente para formar novos cirurgiõesdentistas que respondam às demandas sociais, reforçando o compromisso de devolver à sociedade tudo que aprenderam. O presente estudo teve como objetivo analisar a percepção de alunos do curso de graduação em Odontologia da Universidade Federal do Rio Grande do Norte (UFRN) a respeito do papel do professor no processo ensino-aprendizagem.

\section{PROCEDIMENTOS METODOLÓGI- COS}

O estudo foi de natureza qualitativa, utilizando a técnica de grupo focal para a coleta de dados. Investigar o papel do professor no processo de ensino-aprendizagem em um curso de graduação em Odontologia implica em explorar as percepções experimentadas pelos alunos deste curso. O projeto de 
pesquisa foi submetido e aprovado pelo Comitê de Ética em Pesquisa HUOL-UFRN por meio do parecer 16654/2012.

O público-alvo da pesquisa foi composto por estudantes regulamente matriculados nos períodos iniciais (ingressantes) e finais (concluintes) do curso de Odontologia da UFRN, no ano 2012, visando colher a percepção do estudante nos mais diferentes momentos da graduação. Dessa forma, os alunos dos períodos iniciais avaliaram o desempenho dos professores do ciclo básico, já os alunos concluintes avaliaram os professores de todo o curso.

O recrutamento dos alunos aconteceu a partir da homogeneidade sendo respeitada a variabilidade dos participantes, incluindo estudantes do sexo masculino e feminino bem como com diferentes formas de desempenho no curso. Houve uma articulação prévia com alunos-chave em todas as turmas, para explicar os objetivos da investigação, solicitar a colaboração e agendar a reunião, sendo incluídos no estudo os que concordaram em participar da pesquisa e os que tiveram disponibilidade, tempo e facilidade de contato $^{8}$. Todos os participantes leram e assinaram o termo de consentimento livre e esclarecido anteriormente ao desenvolvimento dos grupos focais. Alunos transferidos e reprovados foram excluídos da pesquisa procurando evitar viés de informação.

Os grupos focais foram desenvolvidos em sala de aula no Departamento de Odontologia da UFRN, com cadeiras dispostas em círculo para permitir melhor campo de visão e de comunicação entre os participantes. Todos os grupos focais foram conduzidos por uma equipe de pesquisa composta por um pesquisador facilitador e um pesquisador observador, sendo papel do facilitador conduzir o processo utilizando um roteiro de entrevista semiestruturada e o observador para identificar aspectos pertinentes ao processo, como algumas percepções físicas, posturais e de entonação durante os discursos dos estudantes, além do controle da gravação das falas. Após serem acomodados na sala, os participantes receberam um agradecimento pela aceitação de participação da pesquisa, foram apresentados entre si e iniciada a dinâmica do grupo focal.

Todas as atividades do grupo focal foram gravadas e transcritas para posterior análise do material. As fases do processo foram elaboradas e discutidas pelo grupo de trabalho composto por alunos do Projeto de Ações Acadêmicas Integradas Associadas da UFRN.

As ideias, sentimentos e avaliações foram analisados por meio da técnica de análise temática categorial ${ }^{9}$. Este estudo é parte de uma pesquisa mais ampla, o qual envolveu a percepção dos alunos dos períodos iniciais e concluintes do curso de Odontologia da UFRN relativas à contribuição do ciclo básico para a formação em Odontologia.

\section{RESULTADOS E DISCUSSÃO}

As percepções dos estudantes sobre o papel dos professores no processo ensinoaprendizagem durante sua formação acadêmica no curso de Odontologia foram agrupadas nas categorias: (a) metodologia adotada pelo professor; (b) relacionamento professor/aluno como influente no processo de aprendizagem; (c) falta de autonomia do discente; (d) desenvolvimento docente.

Destas categorias, puderam ser analisadas as seguintes perspectivas:

\section{(a) Metodologia adotada pelo professor}

Na percepção dos estudantes a metodologia adotada pelo professor é um fator determinante no processo ensinoaprendizagem e constitui uma importante 
ferramenta facilitadora da aprendizagem, tornando-se responsável pelo entendimento e por desenvolver no estudante o interesse pelo componente curricular e pelo conteúdo ministrado.

Para isso, as experiências mais significativas na visão dos estudantes foram em disciplinas cujos professores conseguem relacionar o conteúdo teórico com a Odontologia e sua prática, fazer uma articulação entre os conteúdos, utilizando resolução de casos clínicos, além da realização de práticas laboratoriais, seminários e atividades de campo.

"Eu acho que a gente pode destacar [disciplina do $1^{o}$ período]. O professor tinha uma metodologia diferenciada, ele fazia com que o aluno participasse, eu lembro que uma vez a gente tava, eu digo meu deus, era uma simulação que a gente fez. Todo mundo ficou em pé, fez um círculo, então assim, foi uma dia que eu acho que todo mundo se lembra dessa aula, porque o professor fez com que todo mundo participasse. Ele fez com que a gente lembrasse dessas coisas" (concluinte).

Apesar de os alunos terem relatado que era importante o professor ser dentista, o simples fato de o professor conseguir fazer a relação do que está sendo visto em sala de aula com o processo de formação do estudante, transforma o assunto "maçante" em algo significativo. Isso fez com que o estudante se empenhasse mais por considerar que aquele conhecimento que será utilizado no futuro. As citações a seguir mostram isso:

"O que melhorou talvez o ciclo básico tenha sido isso, que algumas disciplinas têm professor dentista e sabem o que direcionar, e alguns ainda estudaram na UFRN $e$ sabem qual a situação" (ingressante).

“...mesmo a gente pagando com professores dentistas a gente não vê a relação com Odonto. É a disciplina mais difícil, mais cobrada e a gente não usa pra nada e no semestre seguinte a gente paga [...] oral e aí sim a gente tá no paraíso" (ingressante).

É fundamental o uso de metodologias ativas de ensino-aprendizagem que permitam a construção do conhecimento baseados em problemas da realidade, bem como integrar os conteúdos básicos e profissionalizantes, teóricos e práticos, para superar os limites da formação e das práticas clínicas tradicionais ${ }^{10}$. Em certos componentes curriculares, as falas dos alunos se direcionam para o que propõe a autora.

"O contato, como eu vi, como eu presenciei a alteração na boca da paciente, quando eu pesquisei, eu entendi muito melhor, do que se eu fosse só no livro, ver a imagem...a gente vai para o DOD ver a patologia e pesquisa sobre ela depois de tê-la visto" (ingressante).

"Uma aula que marcou muito assim, mesmo na questão prática, foi aquela em que a professora passou aquela lista de casos pra gente. Que a gente tinha que prescrever uma medicação, eu achei importante, por mais que não fosse a prática em si, mas tenho certeza que muitos de nós gravamos muitos medicamentos ali, entendeu? E conseguimos lembrar, e também o interesse de você pesquisar fora da sala de aula, porque era pra gente resolver a lista e levar no outro dia” (ingressante).

A metodologia adotada pelo professor é tão decisiva na aprendizagem dos alunos, que em disciplinas ministradas por diversos professores com diferentes metodologias, o estudante sente uma maior dificuldade de aprender e realizar a associação dos conteúdos mesmo se tratando de uma mesma disciplina.

“Eu acho que um fator negativo é você ter 
muitos professores em uma disciplina. Tinha disciplina que a gente tinha 6, 7 professores. E isso acaba confundindo assim. A metodologia é diferente. Você faz uma questão de cada prova, é um estilo de cada professor. Então pra você estudar é bem mais difícil” (concluinte).

Entretanto, observa-se que não é só a quantidade de professores e sim a falta de articulação entre eles que prejudica o aprendizado. Quando não há comunicação e metodologias que se cruzem o processo educativo se torna frágil, sem permitir que o aluno veja relação entre os conteúdos ministrados em um mesmo componente curricular. Isto torna o ensino estanque e fragmentado que é característica de práticas de ensino tradicional.

" $E$ isso depende do professor, porque o aluno estuda se o professor puxa e se ele acha a matéria interessante. E também estuda pra prova pra tirar um dez. Estuda meio que obrigado..." (ingressante).

Em algumas situações como esta, o aluno questiona, durante o processo de aplicação da avaliação escrita, quem é o professor responsável pela questão uma vez que a resposta será diferente dependendo de quem construiu a questão. Ainda em relação ao sistema de avaliação, um fator problemático citado pelos discentes foi o estabelecimento de metas dentro das clínicas. Este sistema consiste em determinar um número mínimo de procedimentos a serem realizados durante o semestre nas disciplinas clínicas, para que o aluno obtenha sua nota final. As metas levam em consideração apenas a quantidade de procedimentos realizados, em detrimento da saúde do paciente, uma vez que não o veem de forma integral, já que não atendem todas as suas necessidades. Alguns alunos referiram até como sorte (positivamente) encontrar um paciente com muitos problemas de cárie, para fazerem mais restaurações e cumprirem as metas. Isso mostra que essas metas são um fator condutor à alienação e à quebra dos preceitos do Sistema Único de Saúde (SUS). Isto pode ser mensurado por meio das seguintes citações:

"Cada clínica vai aumentando as metas que são por procedimentos. $O$ aluno tem que fazer aquilo. Não é ético que a gente tenha que dispensar o paciente sem concluir o tratamento porque precisamos cumprir as metas" (concluinte).

"Qual é o critério de seleção, qual é o critério de triagem da clínica? É a meta ou é a saúde bucal do paciente? E qual é a nossa meta? É tratar o nosso paciente fixo como uma pessoa ou tratar o avulso como um indigente. Porque se o paciente avulso tem a produção que não conta, então ele é o que? Ele é paciente, ele é o que?" (concluinte).

Ainda em alguns relatos é possível observar a presença da pedagogia tradicional, na qual o ensino está centrado no professor. Essa estratégia tradicional de ensino, onde as ideias e os conhecimentos são os pontos mais importantes da educação, acaba desencadeando o papel do aluno apenas de receber o que o professor lhe oferece, levando-o à memorização, à passividade e muitas vezes ao esquecimento $^{11}$. Além disso, predomina a distância entre teoria e prática, falta de problematização e de conhecimento da realidade social.

\section{(b) Relacionamento professor/aluno como influente no processo de aprendiza- gem}

Outra característica bastante significativa dentro da pesquisa, citada pelos discentes, foi a relação entre o professor e o aluno como determinante no processo de aprendizagem. Para os estudantes se aprende mais rápido e melhor disciplinas em que há uma 
empatia com o professor e também com sua metodologia.

Assim, verifica-se que para a aprendizagem é importante um vínculo que aproxime os atores do processo (professores e alunos). Além disso, dentro das instituições de educação da área de saúde existe o ator paciente, que também é de suma importância para o estabelecimento desta educação, uma vez que ele representa a sociedade em que o profissional irá atuar. Conforme a maneira que essa interação se dá, entre estes atores, a aprendizagem do aluno pode ser mais ou menos facilitada.

"Então assim, a disciplina é difícil, mas a partir do momento que houver um bom relacionamento do professor aluno, aquilo ali se torna melhor" (concluinte).

Uma linha de pesquisa em Psicologia Educacional vem mostrando que ao invés do que se pensava antes não são as características de personalidade do professor e sim suas ações, seu relacionamento com os alunos em sala de aula que influenciam diretamente na aprendizagem $^{12}$. Entre os vários ambientes de ensino, as relações entre professores e alunos despontam como uma das principais matrizes de interação, na qual se apresentam valores, comportamentos, afetos que são veiculados subliminarmente durante a transmissão de conhecimentos e técnicas, e vão participando da construção da atitude profissional ${ }^{13}$. Portanto, nessa relação professor-aluno deve ser estabelecido um clima que facilite a aprendizagem, a partir de determinadas qualidades de comportamento do professor, como autenticidade, apreço ao aluno e empatia.

Contudo, deve-se buscar estabelecer essa relação entre professor e aluno de forma harmoniosa, em que o docente seja capaz de perceber sua importância na aprendizagem efetiva dos alunos, procurando assim atuar como facilitador do processo de ensino- aprendizagem, desenvolvendo uma relação mais aberta, de maior proximidade com os estudantes, tornando-os sujeitos e responsáveis por sua aprendizagem, no sentido de considerá-los como participantes ativos do processo de construção de seu conhecimento. Entretanto, este "bom” relacionamento não pode comprometer a efetividade do aprendizado.

"E tinha a disciplina [ ], que pobre coitado do professor, achava que tava sendo bom pra turma, dispensava a turma, "maneirava”, fazia prova em dupla, era super tranquilo, prova com consulta, mesmo sem consulta todo mundo olhava o livro ele achava que estava fazendo o bem pra gente e a gente também achava que estava se fazendo o bem porque a gente ia passar nas outras disciplinas, passar em [ ], mas só depois quando fomos precisar de [ ], já era tarde demais" (ingressante).

Estas situações, muitas vezes sujeitam o professor a fazer escolhas, uma vez que num contexto onde você tem várias disciplinas, com abordagens diferentes e cobranças diferenciadas, alguns acabam entendendo que sua maior contribuição para o aluno seria permitir que ele tivesse menor perspectiva de aprendizado, mas maior possibilidade de sucesso (aprovação) em todas as disciplinas.

\section{(c) Falta de autonomia do discente}

Os estudantes se mostraram passivos quanto ao seu aprendizado, de forma a se subjugarem aos níveis de hierarquização enraizados no processo de ensino, onde o professor ensina e o aluno aprende. Isto é reflexo da falta de protagonismo dos discentes que não se sentem corresponsáveis por gerir seu aprendizado, atribuindo apenas ao professor esta tarefa.

"E isso depende do professor, porque o aluno estuda se o professor puxa e se ele 
acha a matéria interessante [...]. Estuda meio que obrigado, mas se o professor ele usa uma metodologia ímpar, uma coisa que empolgue o aluno. Então, com certeza o aluno se sente estimulado" (concluinte).

As metodologias de ensino tradicionais com aulas expositivas são preferidas pelos estudantes que acham a posição de ouvinte confortável, principalmente se o professor torna a aula interessante ${ }^{14}$. Assim, para evitar o enfretamento de dificulades, os alunos fogem das metodologias que os levem a problematizações e questionamentos, e esperam dos professores ensinamentos concretos e que transmitam certezas.

A autonomia dos estudantes não pode ser ensinada, deve ser conquistada, construída individualmente, uma vez que ninguém é sujeito da autonomia de niguém ${ }^{15}$. Ensinar exige respeito à autonomia do educando ${ }^{15}$, assim cabe ao professor respeitar as diferenças dos diversos seres ímpares sujeitos da sua aprendizagem e saber que cada um deles tem dificuldades e tempos diversos de aprendizado.

\section{(d) Desenvolvimento Docente}

O nível de exigência e de especialização de alguns professores em relação a suas disciplinas foi um fator bastante abordado, mostrando que ao invés de criarem recursos para despertar o interesse do estudante pelos conteúdos ministrados esses professores acabaram impondo um conhecimento com grau de especificidade tão elevado que muitas vezes torna-se incompatível com a graduação, tendo em vista a pouca aplicação desses conhecimentos a um clínico geral.

"Tudo isso é questão de formação, às vezes a gente sai, tipo assim, a gente encarna, sai do segundo período um antropólogo, um imunologista, por causa disso sabe? Porque é muito assim, uma profundi- dade, eles aprofundam de uma forma bastante e não fazem aquela integração como que eu acho que deveria com a Odontologia” (ingressante).

"A disciplina de [ ] era uma exigência muito grande, era uma cobrança muito grande, nós tínhamos que aprender todas as cascatas imunológicas e a gente decorava tudo e a gente ficava pensando... “ caramba será que um dia eu vou precisar disso'” (concluinte).

"E quanto à [ ] também, é como se fosse um mestrado e um doutorado." (concluinte).

Apesar disso, inferiu-se com a pesquisa que as relações de poder permeiam a estrutura universitária e, em particular, o curso de Odontologia, seja pelas relações intrínsecas entre professor e aluno, como também pela postura pedagógica adotada pelo professor. O depoimento a seguir traduz essa assertiva dentro do próprio universo dos educandos ao questionar como o professor reduz sua proposta pedagógica à sua titulação maior.

"Mas eu acho que alguns professores aqui não estão preparados pra dar aula, eles estão preparados pra mestrado, doutorado, pesquisa, extensão. Dar aula em si, aluno e professor eu acho que muitos aqui precisam aprender" (ingressante).

A formação do professor se dá, atualmente, como subordinado a concepções pré-estabelecidas, herdadas dos programas de pós-graduação. De tal forma que há uma tendência a serem os novos docentes espelhos dos professores que os formaram, gerando um ciclo vicioso, assumindo personalidades, posturas e formas de ensinar repetidas e em algumas situações inadequados à formação em Odontologia.

São poucos os programas que incluem a pesquisa educativa (pedagógica) em seus currículos $^{16}$. Uma das principais finalidades 
do mestrado deveria ser a formação docente, uma vez que a visão desses cursos deveria estar voltada a preparar um professor que capacitasse alunos da área da saúde a atuar com perspectiva generalista, com sólida formação ética e humanística, preparados para proporcionar a transformação da sociedade ${ }^{17}$.

\section{CONSIDERAÇÕES FINAIS}

O paradigma da educação centrada no aluno como sujeito ativo de sua aprendizagem, mediado por um professor que respeita a autonomia do aluno e constrói junto com ele o aprendizado necessário para sua formação, ainda configura-se como um dos maiores desafios no contexto da educação em Odontologia.

Coerente com uma proposta de ensino ainda bastante focada no conteúdo, é o professor, com sua formação em área específica do conhecimento e responsável exclusivo pelo processo de avaliação de desempenho dos estudantes, ainda hoje, o centro da condução da formação em Odontologia. Apesar de absolutamente pronto a responder sobre as principais inovações de sua área (especialidade), grande parte dos professores mantémse distante das abordagens pedagógicas contemporâneas, dificultando a possível posição de protagonismo do aluno em seu processo formativo.

A passividade dos discentes, oriundos de um sistema educacional historicamente consolidado na transmissão de conteúdos unilaterais voltado para o ingresso destes alunos na educação superior e o papel dos professores como centro do processo ensinoaprendizagem são barreiras ainda presentes na consolidação da formação de um novo profissional de saúde.

Ademais, o pouco espaço proporcionado na maioria dos programas de pósgraduação, responsáveis pela formação de mestres e doutores, para a discussão de tecnologias educacionais voltadas para a integração dos vários campos de saber (interdisciplinaridade) e construção do conhecimento contribuem significativamente para a dificuldade no movimento de consolidação de práticas pedagógicas necessárias a formação de profissionais generalistas, críticos e socialmente responsáveis pela contribuição da formação na área da saúde.

Faz-se também necessário compreender a necessidade da ampliação de cenários de aprendizagem que envolvam os serviços públicos de saúde, permitindo integração de conteúdos, articulação com a equipe de saúde e, principalmente, identificação pelos professores do Sistema Único de Saúde, fundamental na formação de recursos humanos na área da saúde, enriquecida pela perspectiva de identificação real das necessidades da população. Com isto, processos avaliativos focados na produção de procedimentos odontológicos, com finalidade única de garantir algum adestramento mecânico, tendem a ser superados. Ainda nesta perspectiva, a humanização do atendimento pode se configurar mais como princípio ético do que como "matéria" a ser ensinada para seres humanos, alunos ou professores.

Para enfrentar este desafio, a metodologia da problematização tem-se apresentado como apropriada alternativa para atender as exigências de transformação, pois nessa "era da informação" os conhecimentos envelhecem muito rapidamente, e o mais importante não são as informações, mas sim fazer o aluno pensar na realidade ${ }^{18}$. Logo, o uso dessa metodologia nos cursos de Odontologia, possibilitaria o desenvolvimento integral do papel do profissional que poderia responder as demandas ${ }^{19}$ da sociedade com maior propriedade e reflexão crítica no seu espaço de trabalho, o que culminaria em melhoria da qua- 
lidade da assistência prestada.

É necessário compreender que ensinar é fazer pensar, é despertar o interesse do estudante em buscar conhecimento (para além da informação), estimulando-o a construir, desconstruir e reconstruir o seu conhecimento.

\section{REFERÊNCIAS}

1. Pizzatto E, Garbin CAS, Garbin AJÍ, Saliba, NA. O papel do professor no ensino odontológico. Saúde Debate 2004; 28 (66):52-7.

2. Cerqueira TCS. O professor em sala de aula: reflexão sobre os estilos de aprendizagem e a escuta sensível. PSIC 2006;7(1):29-38.

3. Cyrino EG, Toralles-Pereira ML. Trabalhando com estratégias de ensinoaprendizado por descoberta na área da saúde: a problematização e a aprendizagem baseada em problemas. Cad Saúde Públ. 2004; 20(3):780-8.

4. Garbin CAS, Saliba NA, Moimaz SAS, Santos KT. O papel das universidades na formação de profissionais na área de saúde. Rev ABENO 2006;6(1):6-10.

5. Cunha MI. Diferentes olhares sobre as práticas pedagógicas no Ensino Superior: a docência e sua formação. Educação 2004; 3(54):525-36.

6. Toassi RFC. Integrated curriculum for teaching dentistry: new directions for training in the field of healthcare. Interface (Botucatu) 2012;16(41):529-42.

7. Lazarrin HC, Nakama L, Júnior LC. Percepção de professores de Odontologia no processo de ensino-aprendizagem. Ciênc Saúde Colet. 2010; 15(Supl.1):1801-10.

8. Turato ER. Tratado da metodologia da pesquisa clínico-qualitativa. Petrópolis: Editora Vozes, 2003.
9. Bardin L. Análise do discurso. Lisboa: Edições 70, 1977.

10. Feurwerker LCM, Sena RR. A contribuição ao movimento de mudança na formação profissional em saúde: uma avaliação das experiências UNI. Interface (Botucatu) 2002;6(10):37-50.

11. Cunha MI. O professor universitário na transição dos paradigmas. Araraquara: JM Editora, 1998.

12. Santos SC. O processo de ensinoaprendizagem e a relação professoraluno: aplicação dos "sete princípios para a boa prática na educação de ensino superior”. Cad Pesq Adm. 2001; 8(1): 69-82.

13. Rios IC, Schraiber LB. A relação professor-aluno em medicina - um estudo sobre o encontro pedagógico. Rev Bras Educ Med. 2012;36(3):308-16.

14. Lemos CLS. A implantação das Diretrizes Curriculares dos Cursos de Graduação em Odontologia no Brasil: algumas reflexões. Rev ABENO 2005;5(1):80-5.

15. Freire P. Pedagogia da autonomia: saberes necessários à prática educativa. 25. ed. São Paulo: Paz e Terra, 2002.

16. Perri de Carvalho AC. Ensino de Odontologia em tempos de LDB. Canoas: ULBRA, 2001

17. Noro LRA, Albuquerque DF, Ferreira MEM. O desenvolvimento do processo ensino-aprendizagem: visão do aluno e do professor. Rev ABENO 2006; 6(2): 109-14.

18. Bordenave JD, Pereira AM. Estratégias de ensino-aprendizagem. Petrópolis: Ed. Vozes, 2002.

19. Ribeiro LRG, Nery IS, Nogueira LT, Bonfim EG. O desafio de implantar a sistematização da assistência de enfermagem sob a ótica de discentes. Esc Anna Nery 2007;11(3):459-65. 


\section{ABSTRACT \\ The teacher (still) in the center of the teaching-learning process in Dentistry}

There is recognition of the need for change in education of health professionals to face the need to train professionals able to respond to social demands and bring with it higher quality of life for the population. For this, it is essential to discuss how the teacher fits in this context since it is their responsibility for the conduct of the educational process. The aim of this study was to analyze the perception of undergraduate students of dentistry at the Federal University of Rio Grande do Norte (UFRN) about the role of the teacher in the teaching-learning process. This is a qualitative study, conducted by the technique of focus groups composed of regular students of $2^{\text {nd }}, 3^{\text {rd }}, 4^{\text {th }}, 8^{\text {th }}$, and $9^{\text {th }}$ periods/semesters, in the year 2012. Respondent students em phasized the teacher as largely responsible for their learning, in so being in the center of the teaching-learning process. In analysis of the data, four categories emerged: methodol- ogy adopted by the teacher, teacher / student relationship as influential in the learning process, lack of autonomy for the student, and teacher training. The study showed that the teacher is still kept in the center of the teaching process according to the passivity of students in not taking their role as coresponsible for their learning, possibly because of the stance taken by the teacher, focused more on technique and with little basis in active teaching methodologies. In other words, not enough hands-on learning methodologies/activities are being implemented by the teachers.

Descriptors: Teaching. Faculty Dental. Staff Development. Dentistry.

Correspondência para:

Luiz Roberto Augusto Noro

e-mail: luiz_noro@hotmail.com

Departamento de Odontologia da UFRN

Avenida Salgado Filho, 1787

59056-000 - Natal/RN 